\title{
Study of loading waveform, loading duration, rest period and stress level on fatigue life of asphalt mixtures
}

\author{
Ali MansourKhaki*, Alireza Samdzadeh and Majid Jebalbarezi
}

\begin{tabular}{|c|c|}
\hline $\begin{array}{l}\text { ART ICLE INGO } \\
\end{array}$ & A B S T RACT \\
\hline $\begin{array}{l}\text { Article history: } \\
\text { Received October 6, } 2014 \\
\text { Accepted } 2 \text { February } 2015 \\
\text { Available online } \\
2 \text { February } 2015 \\
\text { Keywords: } \\
\text { Hot mix asphalt } \\
\text { Fatigue life } \\
\text { Loading waveform } \\
\text { Duration and rest period } \\
\text { xperimental study }\end{array}$ & $\begin{array}{l}\text { The main objective of this paper is to study the effects of haversinse and triangular loading } \\
\text { waveforms on the fatigue life of Hot Mix Asphalt (HMA) specimens. Effects of load duration, } \\
\text { rest period and stress level are also studied for the asphalt mixtures at } 25 \mathrm{oC} \text {. An indirect tensile } \\
\text { test with strain control was performed to determine the fatigue life of asphalt. The fatigue tests } \\
\text { were performed at two stress levels }(170 \text { and } 250 \mathrm{kPa}) \text {, two waveforms (haversine and } \\
\text { triangle), three load duration ( } 100,200,400 \mathrm{~ms}) \text {, and two rest period to load duration ratios ( } 4 \\
\text { and } 9) \text {. The obtained results showed that fatigue life of haversine waveform is less than fatigue } \\
\text { life of triangle waveform. As the area under the loading curve is increased (stress level is } \\
\text { increased or deformed), effect of rest period on the fatigue life decreases. On the other hand, } \\
\text { as the tire contact area is increased, the induced tire pressure reduction decreases its destructive } \\
\text { effects on the asphalt layer. As the load duration is decreased, fatigue life will increase. This } \\
\text { effect is more pronounced for lower stress levels than the higher stress levels. }\end{array}$ \\
\hline
\end{tabular}

\section{Introduction}

Several traffic and environmental factors affect the deterioration of roads. A substantial part of damage on flexible pavements is caused by cracking of the asphalt concrete layer. Different types of cracking such as fatigue cracking and low temperature cracking are frequently occurred in the pavements. Hence, it is important to study the crack growth behavior of asphalt pavements subjected to traffic loads of moving vehicles or thermal stresses induced by the daily or seasonal temperature changes. While at low temperatures the risk of fast brittle fracture in the pavements increases significantly (Kim et al., 2003a; Li \& Marasteanu, 2010; Zegeye et al., 2012; Ameri et al., 2011, 2012; Aliha et al., 2014), at higher temperatures other failure modes such as rutting or incremental and cumulative damages induced by fatigue loads have more destructive effects on the pavements. Fatigue (alligator) cracking is considered to be one of the most significant distress modes in pavement which 
is associated mainly with repeated traffic load. Fatigue of pavements is a very complex phenomenon caused by cyclic loading of traffic passing over the pavement. Fatigue cracking leads to poor pavement performance, which in turn increases maintenance as well as road user cost (Abo-Quadis \& Shatnavi, 2007). Fatigue behavior of asphalt mixtures is dependent on the test type, asphalt mixture specifications and test variables such as loading waveform, level of stress and loading frequency (including load duration and rest period). There are different tests to determine the fatigue of asphalt mixtures. Simple beam with three-point bend, cantilever beam with rotating bending, direct axial, indirect rotating flexural loading, triaxial test and indirect tensile fatigue test are some common types of these tests (Huang, 2004; Tangella et al., 1990; Francken, 2004).

Indirect fatigue tensile test has been widely used to determine the fatigue behavior of asphalt mixtures (Wen, 2001; Witczak, 2002). It can be done in two manners: stress control or strain control. Indirect fatigue tensile test is done by applying compressive load to the cylindrical specimens of approximately $100 \mathrm{~mm}$ diameter and $70 \mathrm{~mm}$ height. It is performed by using rigid loading strips that has been placed in two opposite points in the form of an arc-shape. In general, fatigue cracks are generated under asphalt layer and exactly under loading spot of vehicles' tires. Stress state in these spots is in the form of longitudinal and lateral with vertical compression. It is notable that stress state around the circle of indirect tensile specimens is similar to stress state under the ground asphalt layer. Fracture plane in the indirect tensile test is usually vertical and this issue can be considered as one of the advantages of indirect tensile test. Therefore, this test is suitable for detecting starting spots of tiny cracks and material response to these cracks. It should be mentioned that there is an exact similarity between asphalt compaction direction and critical tensile direction in the indirect tensile test and the asphalt performance for the fatigue cracks (Wen, 2001).

Barksdale (1971) has used finite element and elastic theory to study the vertical compressive stress pulse width. He found that load duration is a function of speed and depth beneath the pavement surface and mixture geometry has no effect on the load duration. He also found that pulse shape varies from an approximately sinusoidal one at the surface to a more nearly triangular one at depths below approximately the middle of the base. Barksdale presented a Table to calculate haversine and triangular load duration based on the speed and depth. For example, haversine load duration for speed of $24 \mathrm{~km} / \mathrm{h}$ in the depth of $20 \mathrm{~cm}$ is 0.1 second. This time for triangular waveform is 0.132 second. Raithby and Sterling (1972) studied loading waveform using axial loading fatigue test. They used haversine and triangular waveforms to express that fatigue life of haversine waveform is longer than triangular waveform. They claimed that it is better to use haversine waveform to calculate fatigue life of asphalt since haversine is similar to what happens in reality. Hu et al. (2010) has shown that load duration is not only a function of speed and depth of layer but also depends on the ratio of dynamical module of asphalt layer and dynamical module of closest layer to the asphalt layer. Hence, squared waveform is recommended in narrow asphalt layers. As the depth of asphalt is increased, it is recommended to use haversine waveform. But in deep asphalt layers with high dynamical module ratio, it is better to use triangular waveform.

According to Porter et al. (1975) frequency of loading in asphalt concrete is defined as number of load cycles subjected to the material per unit of time. Investigation of the effect of loading frequency on fatigue life of asphalt concrete mixtures is difficult because it is interconnected with the load duration and rest period. Changing any of these variables will change the other variables. Hsu and Tseng (1996) have studied the effects of rest period on the fatigue life of asphalt concrete using three point bending test. They studied three different rest period ratios and concluded that rest period has considerable effects on the asphalt fatigue life and by increasing the rest period, fatigue life of asphalt is also increases. Kim et al. (2003b) studied the effects of rest period on fatigue life of asphalt mixtures by using dynamic mechanical analysis test. They first applied 10 rest periods of 2 minutes to asphalt specimens under $\% 0.28$ strain and then compared the obtained results with the tests with no rest period and they observed that this process will improve fatigue life of asphalt mixtures. Kim et al. (2003b) 
mentioned that it could be one of the reasons of inconsistency between the fatigue life generated by predictive models of fatigue life and the fatigue life of asphalt determined by field study. Deacon (1965) studied the effects of load duration on the asphalt fatigue life while the ratio of rest period to the load duration was fixed. He observed that fatigue life of asphalt mixtures is decreased by increasing the load duration. Pell (1961) used bending and torsional tests to control stress and strain, respectively and then concluded that decreasing load duration (increasing vehicle speed) will increase fatigue life in both tests. He also mentioned that there is an inverse linear relation between the stress applied to sand-sheet specimen and its fatigue life in the stress control test, when the specimen's fatigue life is beyond 10000 cycles. Al-Khateeb and Ghuzlan (2014) used indirect tensile test and observed that increasing loading frequency and decreasing stress level will increase fatigue life of asphalt mixtures. Also in higher frequencies, decreasing loading stress level will increase the fatigue life of asphalt mixtures. Epps and Monismith (1972) studied the effects of loading frequency by fixing load duration. They observed that fatigue life does not change in the range of 0 to $30 \mathrm{rpm}$ loading frequencies (Fakhri, 1997). Deacon (1965) showed that if loading frequency increases from 30 to $100 \mathrm{rpm}$, fatigue life will decrease. Raithby and Sterling (1972) studied load duration and rest period using direct tensile test. They used two load duration of 40 and $400 \mathrm{~ms}$. The rest period was varied from 0 to 1 second for the load duration of $40 \mathrm{~ms}$ and from 0 to $800 \mathrm{~ms}$ for the load duration of $400 \mathrm{~ms}$ in their study. They concluded that asphalt mixtures with load duration of $400 \mathrm{~ms}$ have lesser fatigue life. Also effects of rest period in load duration of $40 \mathrm{~ms}$ is much more than its effects in load time of $400 \mathrm{~ms}$. In the other words, rest period effects will decrease by increasing load duration. In this research the effect of loading type (i.e. haversinse and triangular loading waveforms) is studied experimentally on fatigue life of an asphalt mixture. Moreover, the influence of other affecting parameters such as load duration, stress level and rest period is investigated on the fatigue behavior of tested asphalt mixtures.

\section{Research approach}

To reach the objectives of this study, we first determined the optimum content of Hot Mix Asphalt (HMA) specimens using Marshall method. Using the optimum percentages of HMA composition, a few cylindrical shape specimens were manufactured by means of gyratory compactor machine. The air void content of manufactured samples was determined approximately $4 \%$ which demonstrate the validity of process used for manufacturing the asphalt samples. The specimens were then tested using indirect tensile shape specimen by means of a universal testing machine.

\subsection{Material Used}

\subsubsection{Aggregate}

The aggregate used in this study was crushed limestone aggregate. The limestone was obtained from Az-Chenan mine which is located near Tehran. Table 1 shows summary of physical attributes of the used mineral aggregates. Maximum nominal aggregate size used in this study was $12.5 \mathrm{~mm}$. The aggregate gradations are presented in Fig. 1.

\section{Table 1}

Properties of aggregate

\begin{tabular}{lll}
\hline Test Result & Standard & Test \\
\hline Los Angeles abrasion loss (\%) & AASHTO T96 & $22 / 3$ \\
Tow fractured faces (\%) & ASTM D5821 & 93 \\
Absorption coarse aggregate & ASTM C127 & $2 / 2$ \\
Absorption fine aggregate & ASTM C127 & $2 / 4$ \\
Bulk specific gravity, g/Cm3 & ASTM C127 & $2 / 59$ \\
\hline
\end{tabular}




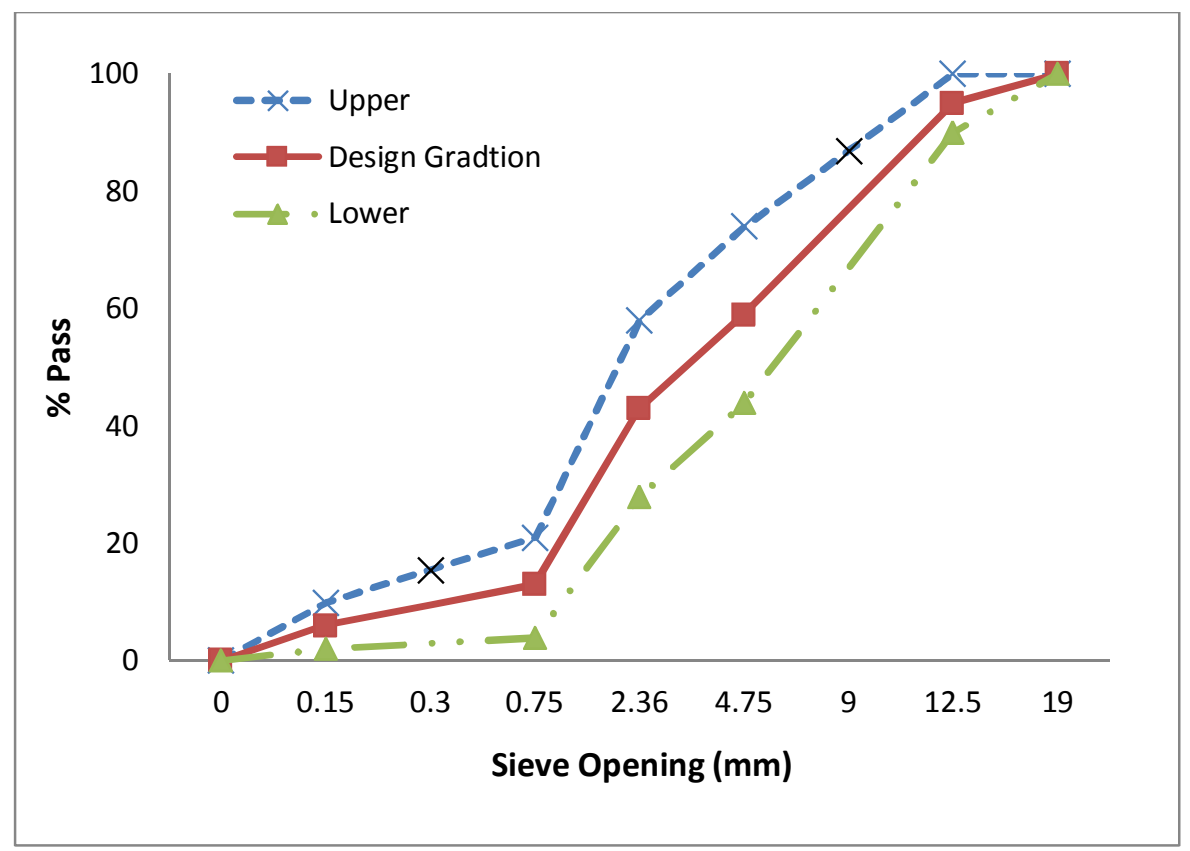

Fig. 1. Gradation of used aggregate

\subsubsection{Asphalt}

Asphalt binder having a penetration of 60/70 was used for preparing HMA specimens which was obtained from the Pasargad Oil Company (Tehran, Iran). Table 2 summarizes the physical properties of the asphalt.

Table 2

Properties of asphalt binder

\begin{tabular}{lll}
\hline Test & ASTM test designation & Test result \\
\hline Specific gravity at $25^{\circ} \mathrm{C}$ & ASTM D-70 & $1 / 03$ \\
Penetration at $25^{\circ} \mathrm{C}$ & ASTM D-5 & 64 \\
Softening point $\left({ }^{\circ} \mathrm{c}\right)$ & ASTM D-36 & 54 \\
Ductility at $25(\mathrm{~cm})$ & ASTM D-113 & 102 \\
Flash point $\left({ }^{\circ} \mathrm{C}\right)$ & ASTM D-92 & 305 \\
Fire point $\left({ }^{\circ} \mathrm{C}\right)$ & ASTM D-92 & 317 \\
\hline
\end{tabular}

\subsection{Determination Optimum Asphalt Content}

The Marshall method was used for calculating the optimum percentage of asphalt content. Hence, mineral aggregates with different percentages of asphalt binder (i.e. 4 to $6 \%$ with intervals of $0.5 \%$ ) were mixed to obtain the optimum HMA composition. A total number of 15 specimens were tested for investigating the stability, flow, air voids, unit weight, and voids of mineral aggregate. The optimum asphalt content was calculated as the average of asphalt contents that meet the maximum stability, maximum unit weight, and $4.0 \%$ air voids. The resulting optimum asphalt contents were checked to find whether they have achieved the specification limits of the five parameters (stability, flow, air voids, unit weight, and voids in mineral aggregate). The resulting optimum asphalt binder content was $5.1 \%$.

\subsection{Specimens Preparation by Gyratory Compactor Machine}

After obtaining the optimum asphalt content, a number of test specimens were made by a gyratory compactor machine (based on Superpave standard). The produced specimens have approximately 100 
$\mathrm{mm}$ diameter and $68 \mathrm{~mm}$ height. It was observed that the air voids of produced specimens are almost 4 percent which reveals the acceptability of the manufactured specimens.

\subsection{Indirect tensile fatigue test}

An indirect tensile test with strain control was performed to determine the fatigue life of the manufactured asphalt mixtures using the UTM machine. A number of loading cycles were drawn against horizontal permanent deformation to calculate the fatigue life of specimens. Fatigue criteria were specimen fracture or $9 \mathrm{~mm}$ horizontal permanent deformation (based on Khaleed (2000) suggestion). We used two stress levels of 170 and $250 \mathrm{kPa}$, two waveforms (i.e. haversine and triangle), three load durations of 100, 200, $400 \mathrm{~ms}$, and two rest period to load duration ratios of 4 and 9 . All the experiments were conducted at $25^{\circ} \mathrm{C}$. The conducted fatigue tests showed the graph of number of loading cycles versus horizontal permanent deformation has a general trend shown in Fig. 2 . At the zone 1 , the rate of permanent deformation decreases by increasing the number of loading cycles. This rate is constant at zone 2 and increases by the number of loading cycles at zone 3 . Table 3 shows a summary of used variables.

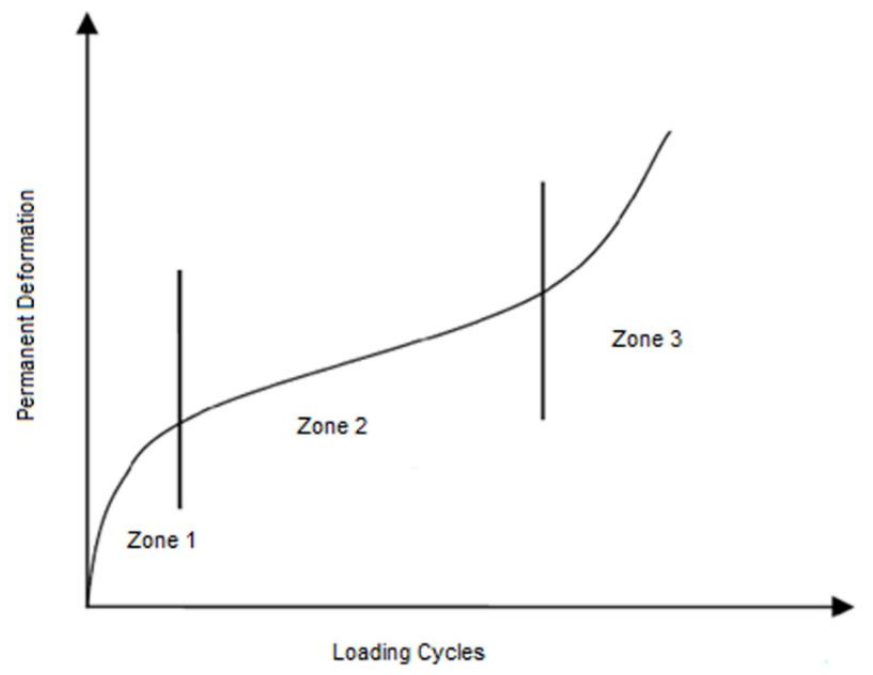

Fig. 2. General trend of permanent deformation based on the number of cycles observed in the indirect fatigue test (Ameri \& mansourian, 2007)

\section{Table 3}

IDT fatigue testing matrix

\begin{tabular}{lll}
\hline Variables (Test Condition) & Number of conducted tests & Value \\
\hline Loading waveform & 2 & Haversien \& Triangle \\
Stress levels $(\mathrm{kPa})$ & 2 & 170,250 \\
load duration $(\mathrm{ms})$ & 3 & $100,200,400$ \\
rest period to load duration ratios & 2 & 4,9 \\
Replicates & 3 & Three IDT fatigue specimens \\
Total number of IDT fatigue tests & $2 * 2 * 3 * 2 * 3=72$ tests & \\
\hline
\end{tabular}

\section{Experimental results}

The main purpose of this research is to study effect of haversine and triangular waveform, rest period and stress level on the fatigue life of asphalt mixtures. To reach this goal, we performed several indirect tensile tests on the hot asphalt specimens, which were made by a gyratory compactor machine. Table 4 shows summary of experimental result. 
Table 4

Result from indirect tensile fatigue test

\begin{tabular}{lllll}
\hline $\begin{array}{l}\text { Level of Stress }(\mathrm{kPa}) \\
\text { Load duration }(\mathrm{ms})\end{array}$ & rest period to load duration ratios & Loading waveform & 170 & Number of Cycles \\
\hline 400 & 9 & Triangle & 6100 & 250 \\
& & Haversine & 4500 & 2100 \\
\hline 400 & 4 & Triangle & 5700 & 2900 \\
& & Haversine & 4200 & 2000 \\
\hline 200 & 9 & Triangle & 22000 & 9700 \\
& & Haversine & 15600 & 6600 \\
\hline 200 & 4 & Triangle & 21700 & 5000 \\
& & Haversine & 14500 & 26700 \\
\hline 100 & 9 & Triangle & 71000 & 19500 \\
\hline 100 & 4 & Haversine & 48900 & 22000 \\
& & Triangle & 70200 & 15900 \\
\hline
\end{tabular}

\subsection{Effect of Load Duration}

The graph of number of loading cycle against load duration shows that the fatigue life of asphalt mixtures decreases noticeably by increasing the load duration (see Figs. 3 and 4). As seen from these figures, the magnitude of reduction in fatigue life increases by increasing the stress level or decreasing the load duration. By comparing Figs 3 and 4, it is seen that the magnitude of reduction of fatigue life with increasing load duration is more pronounced for haversine waveform, since haversine has more area under curve than triangle waveform. It can also be observed that exponential graph is the best fitting curve to determine the magnitude of fatigue life based on the load duration.

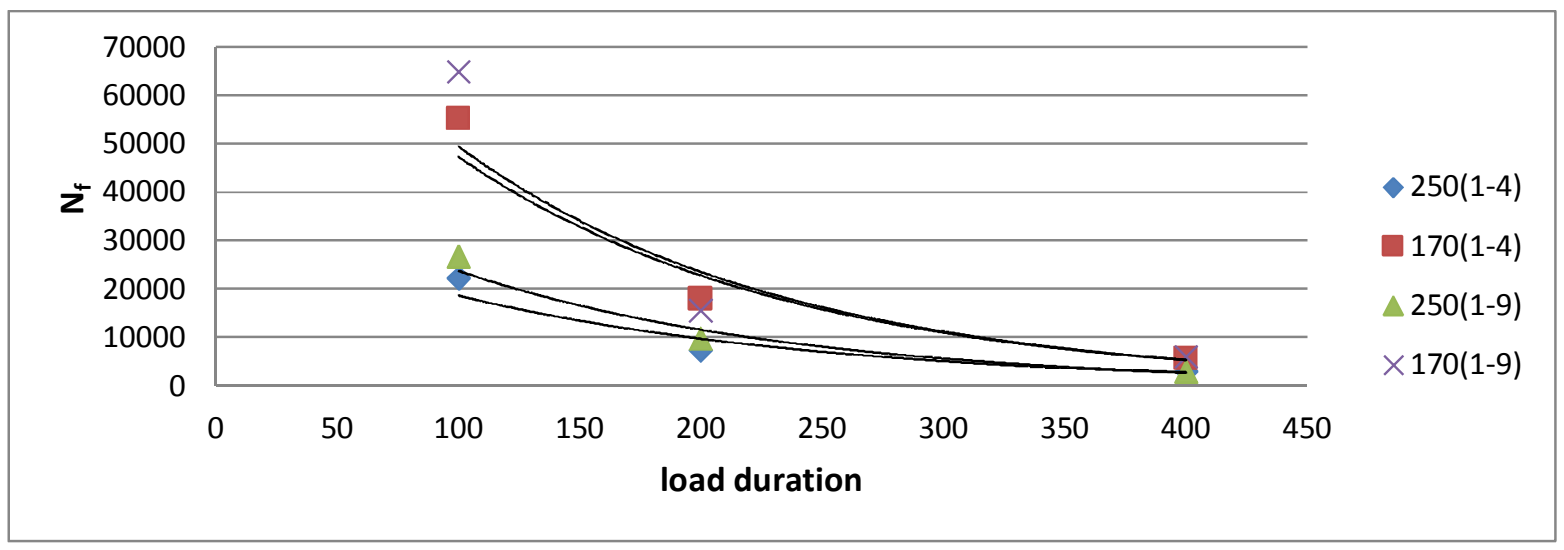

Fig. 3. load duration versus $\mathrm{N}_{\mathrm{f}}$ for triangle load shape

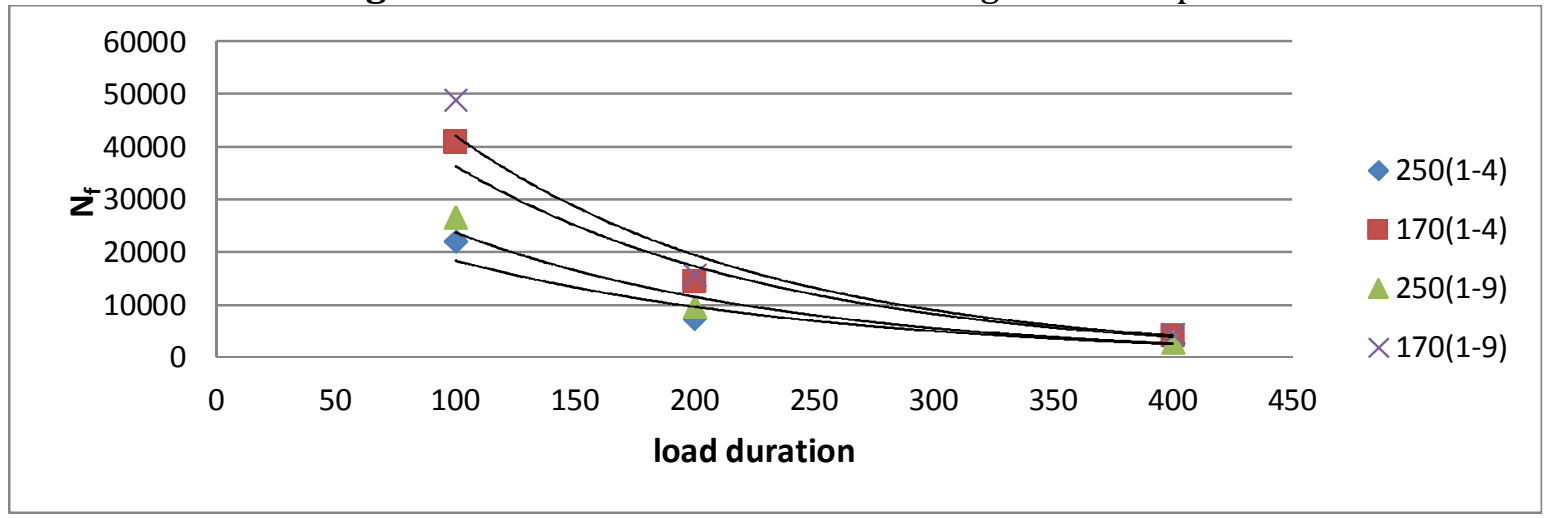

Fig. 4. loadF1 duration versus $\mathrm{N}_{\mathrm{f}}$ for haversine load shape 


\subsection{Effect of Rest Period}

By comparing fatigue life graphs for different rest periods, we can observe that rest period has no effect on specimen displacement at the beginning of second and third phases. Its effect is only on crack growing area in which increases the fatigue life as the rest period increases. On the other hand, it can be concluded from Fig. 5 that effects of rest period decrease in higher load durations and higher stress levels. It is also seen that the time of increasing rest period has more effect on the triangular waveform.

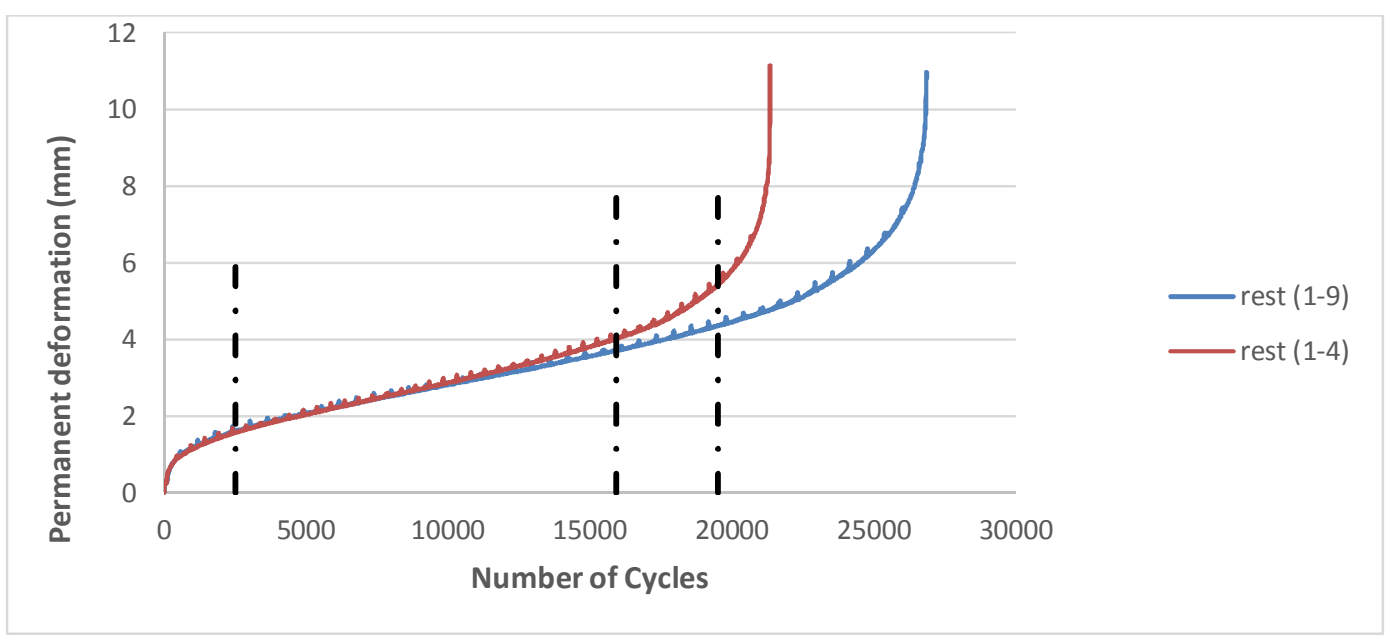

Fig. 5. Effect of stress level on fatigue life (load duration $100 \mathrm{~ms}$ and haversine load shape)

\subsection{Effect of Applied Stress Level}

As we expected, fatigue life will decrease by increasing the stress level. Fig. 6 compares the obtained fatigue behaviors at two stress levels of $170 \mathrm{kPa}$ and $250 \mathrm{kPa}$. By considering deformation at the beginning of phase three, it was observed that the fracture's displacement will increase by increasing the stress level.

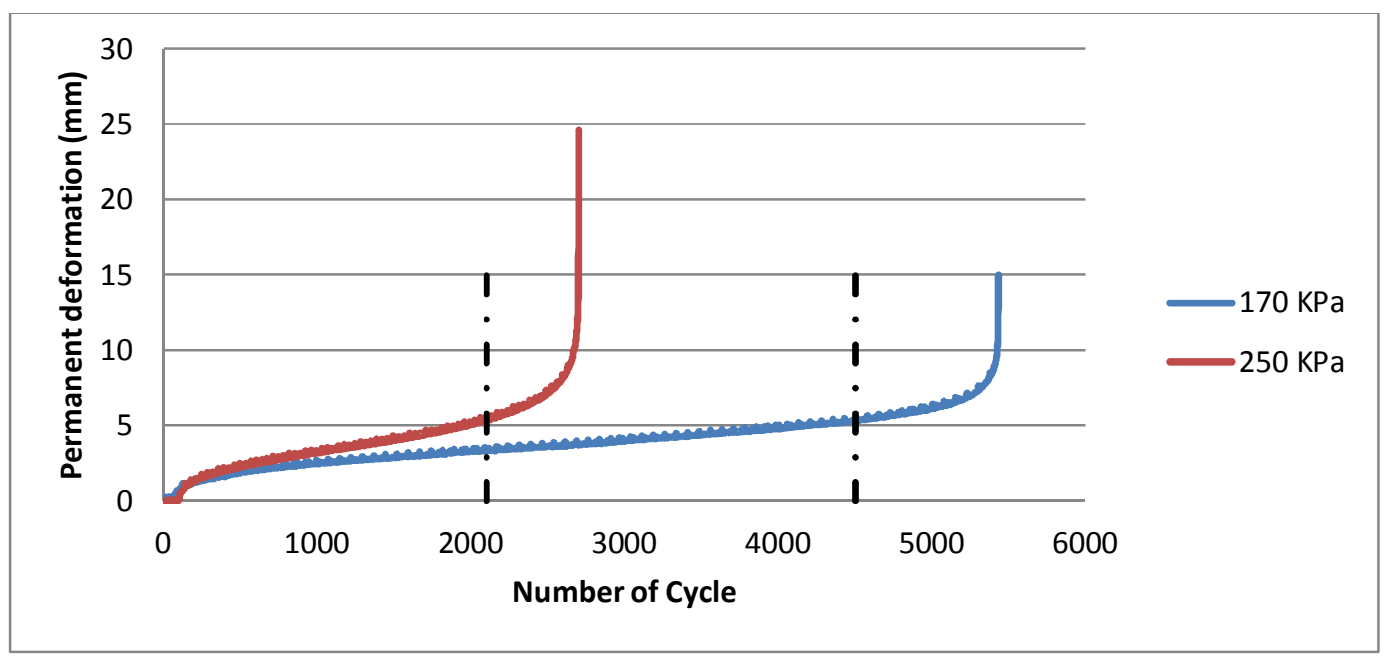

Fig. 6. Fatigue life of haversine waveform for $400 \mathrm{~ms}$ load duration 
Some small cracks were observed at the phase three of the indirect tensile fatigue test. A large crack was then appeared at the middle of specimen by coalescence of the smaller cracks. This crack becomes bigger in each cycle and finally breaks the asphalt specimen. When the specimen breaks, it is in the form of Y shape for stress level of $250 \mathrm{kPa}$ (Fig. 7-a). But when the stress level is $170 \mathrm{kPa}$, specially for $100 \mathrm{~ms}$ loss duration and triangle waveform, the specimen did not fail and only a few cracks were observed till the steel strip falls for $9 \mathrm{~mm}$ and the specimen reached its fatigue life (Fig. 7-b).

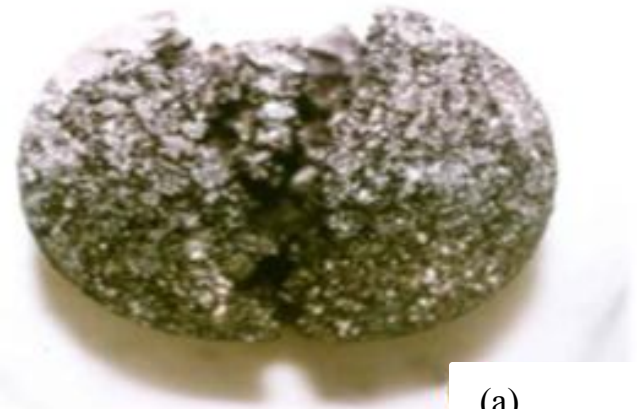

(a)

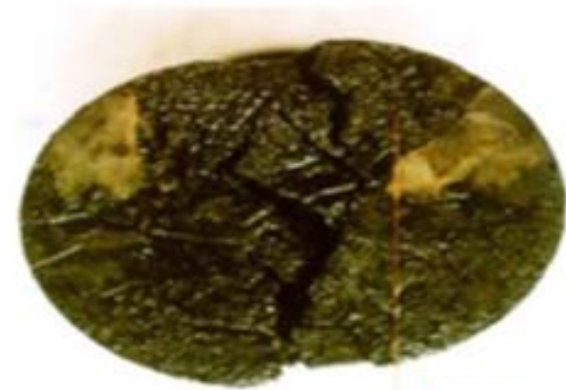

(b)

Fig. 7. Shape of fracture for two stress levels (a) $250 \mathrm{kPa}$ and (b) $170 \mathrm{kPa}$

\subsection{Effect of loading waveform}

The type and time of load in the experimental fatigue tests should be simulated as what happens in reality. When the loads induced by the wheel of a vehicle is far from a specific point in the asphalt pavement, stress is zero on that point and when the load is exactly on that point, the stress is maximum. Therefore, it is logical to assume that a stress pulse is a haversine or triangular waveform. Fig. 8 is a sample graph that shows triangular loading has longer fatigue life than haversine loading. It can be seen that the reduction of load duration has more effect on the triangle waveform. Indeed, by reduction of load duration, triangle waveform shows more increment for the fatigue life of asphalt mixture. This means that as the area under the loading curve increases (stress level increases or is deformed), the effect of loading frequency on the fatigue life decreases, due to total summation of load duration and rest period. On the hand, as the tire contact area is increased, tire pressure reduces and its destructive effects on the asphalt layer decrease especially at higher speeds.

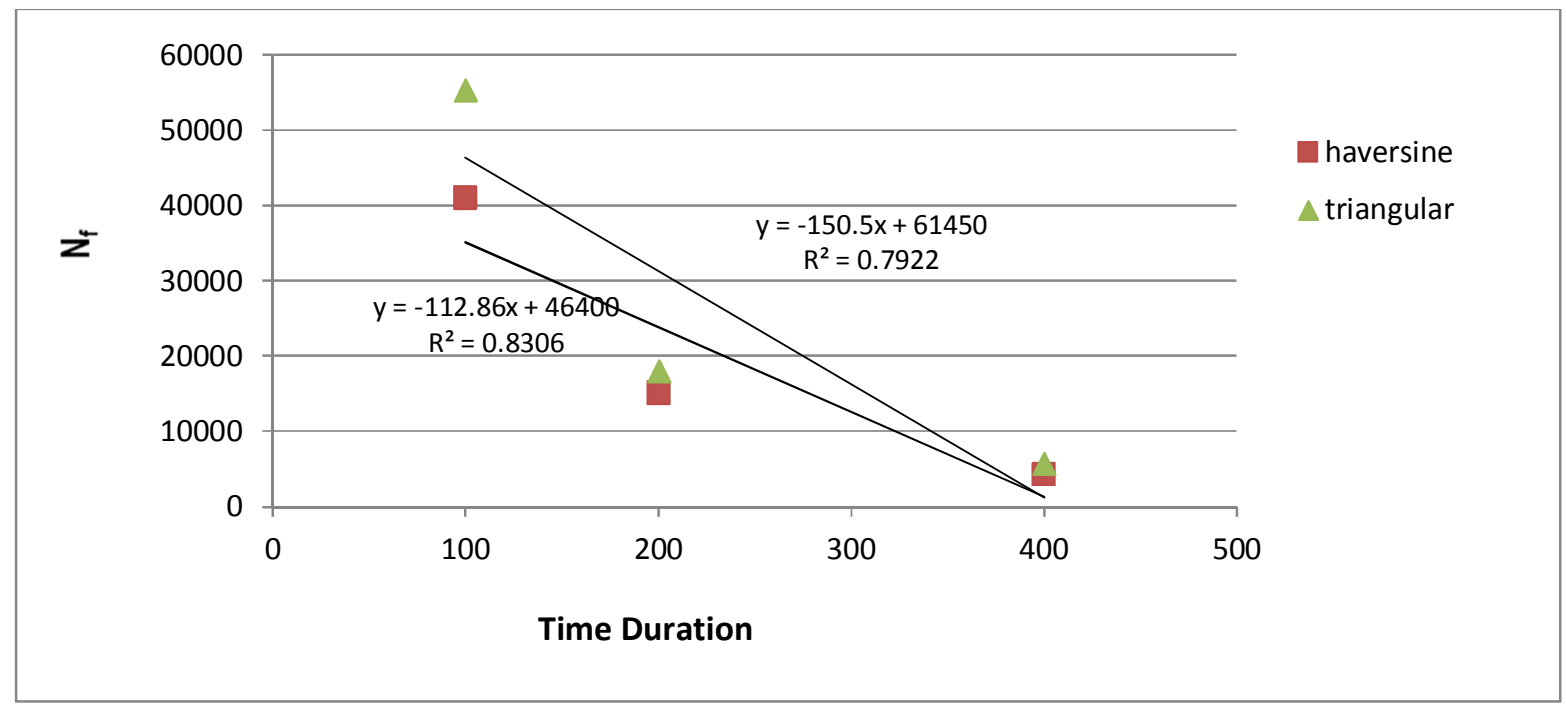

Fig. 8. Nf versus time duration (for stress level of $170 \mathrm{kPa}$ ) 
Also, the fracture strain in Fig. 9, as a sample graph, shows that fracture strain magnitude in the beginning of phase 3 in haversine waveform is more than that in triangular waveform. We can conclude that by using haversine waveform, fracture would be more brittle.

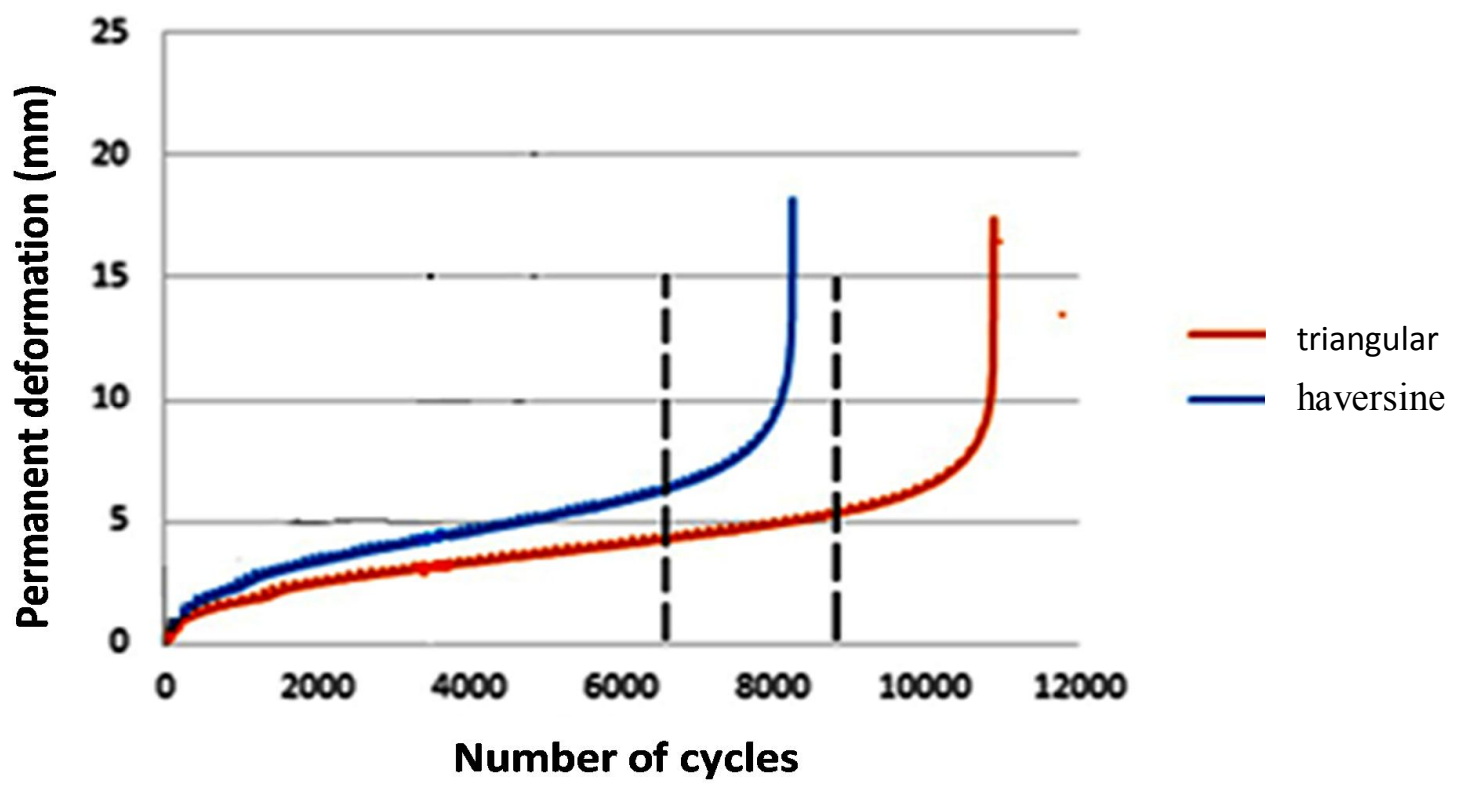

Fig. 9. Fatigue life of haversine and triangle waveforms for $200 \mathrm{~ms}$ load duration

\section{Conclusion}

- In general, Rest period has no effect on the specimen deformation on the beginning of second and third phases of fatigue. It affects only the crack growth stage which increases fatigue life with the increment of rest period.

- As the area under the loading curve is increased (stress level is increased or deformed), effect of rest period on the fatigue life decreases. On the other hand, As the tire contact area is increased, tire pressure reduction, its destructive effects on the asphalt layer decrease.

- In the specimen fracture, fracture shape for is $\mathrm{Y}$ shape for stress level of $250 \mathrm{kPa}$. But, for stress level of $170 \mathrm{kPa}$, specially for $100 \mathrm{~ms}$ loss duration and triangle waveform, the specimen usually does not failure and only a few cracks are observable till the steel strip falls for $9 \mathrm{~mm}$ and the specimen reach its fatigue life.

- As we decrease the load duration, fatigue life will increase. This increment is much more for lower stress levels than higher stress levels.

- In general, if we use a similar load duration and rest period, fatigue life of triangular waveform would be more than fatigue life of haversine waveform.

- Fatigue life will decrease by increasing the stress level. By considering deformation caused at the beginning of third phase we observe that by increasing the stress level, specimen fracture displacement will increase too.

\section{References}

Abo-Qudais, S., \& Shatnawi, I. (2007). Prediction of bituminous mixture fatigue life based on accumulated strain. Construction and Building Materials, 21(6), 1370-1376.

Al-Khateeb, G. G., \& Ghuzlan, K. A. (2014). The combined effect of loading frequency, temperature, and stress level on the fatigue life of asphalt paving mixtures using the IDT test configuration. International Journal of Fatigue, 59, 254-261. 
Aliha, M. R. M., Behbahani, H., Fazaeli, H., \& Rezaifar, M. H. (2014). Study of characteristic specification on mixed mode fracture toughness of asphalt mixtures. Construction and Building Materials, 54, 623-635.

Ameri, M., Mansourian, A., Heidary Khavas, M., Aliha, M. R. M., \& Ayatollahi, M. R. (2011). Cracked asphalt pavement under traffic loading-A 3D finite element analysis. Engineering Fracture Mechanics, 78(8), 1817-1826.

Ameri, M., Mansourian, A., Pirmohammad, S., Aliha, M. R. M., \& Ayatollahi, M. R. (2012). Mixed mode fracture resistance of asphalt concrete mixtures. Engineering Fracture Mechanics, 93, 153167.

Ameri, M., Mansourian, A. (2007). Using the indirect tensile test to present a model to predict the fatigue life of asphalt. Journal of Transportation, Fourth year, NO1, Spring.

Barksdale, R. D. (1971). Compressive stress pulse times in flexible pavements for use in dynamic testing. Highway research record. 345, HRB, National Research Council, Washington, D.C. 3244.

Deacon, J. A. (1965). Fatigue of asphalt concrete (Doctoral dissertation, Institute of Transportation and Traffic Engineering, University of California).

Fakhri, M. (1997). Characterisation of asphalt Pavement materials. University of New South Wales, Sydney, Austeralia.

Hsu, T. W., \& Tseng, K. H. (1996). Effect of rest periods on fatigue response of asphalt concrete mixtures. Journal of Transportation Engineering, 122(4), 316-322.

Hu, X., Zhou, F., Hu, S., \& Walubita, L. F. (2010). Proposed loading waveforms and loading time equations for mechanistic-empirical pavement design and analysis. Journal of Transportation Engineering, 136(6), 518-527.

Huang, Y. H. (2004). Pavement analysis and design. Prentice Hall, Second edition,

Khalid, H. A. (2000). A comparison between bending and diametral fatigue tests for bituminous materials. Materials and structures, 33(7), 457-465.

Kim, K. W., Kweon, S. J., Doh, Y. S., \& Park, T. S. (2003a). Fracture toughness of polymer-modified asphalt concrete at low temperatures. Canadian Journal of Civil Engineering, 30(2), 406-413.

Kim, Y. R., Little, D. N., \& Lytton, R. L. (2003). Fatigue and healing characterization of asphalt mixtures. Journal of Materials in Civil Engineering, 15(1), 75-83.

Li, X. J., \& Marasteanu, M. O. (2010). Using semi circular bending test to evaluate low temperature fracture resistance for asphalt concrete. Experimental mechanics, 50(7), 867-876.

Monismith, C. L., \& Deacon, J. A. (1969). Fatigue of Asphalt Paving Mixtures. ASCE Transportation Engineering Journal, 95(2), 317-346.

Porter, B. W., \& Kennedy, T. W. (1975). Comparison of fatigue test methods for asphalt materials (No. CFHR-3-9-72-183-4 Intrm Rpt.). University of Texas at Austin. Research Report 183-4, Project 3-9-72-183.

Pell, P. S., McCarthy, P. F., \& Gardner, R. R. (1961). Fatigue of bitumen and bituminous mixes. International Journal of Mechanical Sciences, 3(4), 247-267.

Raithby, K. D., \& Sterling, A. B. (1972). Some effects of loading history on the fatigue performance of rolled asphalt. Transport and Road Research Laboratory, Report 496, 7-9.

Francken, L. (Ed.). (2004). Bituminous binders and mixes (Vol. 17). CRC Press.

Tangella, S. C. S. R., Carus, J., Deacon, J. A. \& Monismith, C. L. (1990). Fatigue response of asphaltaggregate mixes. Washington: Strategic Highway Research Program, SHRP-A-404.

Wen, H. (2001). Fatigue performance evaluation of WesTrack asphalt mixtures based on viscoelastic analysis of indirect tensile test. Doctor of Philosophy Thesis, North Carolina State University.

Witczak, M. W., Kaloush, K. T.Pellinen, K. \& El-Basyouny, M. (2002). Simple performance test for superpave mix design. NCHRP 465.

Zegeye, E. T., Moon, K. H., Turos, M., Clyne, T. R., \& Marasteanu, M. O. (2012). Low temperature fracture properties of polyphosphoric acid modified asphalt mixtures. Journal of Materials in Civil Engineering, 24(8), 1089-1096. 